\title{
Undergraduate Mathematics Students Appropriating Programming as a Tool for Modelling, Simulation, and Visualization: A Case Study
}

\author{
Chantal Buteau $^{1} \cdot$ Eric Muller $^{1} \cdot$ Neil Marshall $^{1}$. \\ Ana Isabel Sacristán ${ }^{2}$. Joyce Mgombelo ${ }^{1}$
}

Published online: 4 April 2016

(C) Springer International Publishing 2016

\begin{abstract}
In 2011, the European Mathematical Society stated that a third pillar of scientific inquiry of complex systems has emerged in the form of a combination of modelling, simulation, optimization and visualization. This paper presents a naturalistic case study of an undergraduate student enrolled in a sequence of three programming, project-based mathematics courses at Brock University (Canada) where students learn to design, program, and use interactive environments for the investigation of a mathematics concept, theorem, conjecture, or a real-world situation. We argue that these courses instituted in 2001 aim to develop students' proficiency in the third pillar. Findings from the study suggest that the student engaged in constructionist experiences for learning mathematics through her 14 mathematical programming-based projects, and that she appropriated computer programming as an instrument for engagement in the third pillar.
\end{abstract}

Keywords Programming · Proficiency - Appropriation - University mathematics · Microworld - Constructionism - Third pillar of scientific inquiry of complex systems . Exploratory objects $\cdot$ Instrument

\section{Introduction}

Technology has impacted mathematics as a discipline; for example, experimental mathematics has emerged over the last decades as a new branch "defined less by its

Chantal Buteau cbuteau@brocku.ca

1 Brock University, St. Catharines, ON, Canada

2 Centro de Investigación y Estudios Avanzados del IPN, Ciudad de Mexico, Mexico 
subject matter, and more by its use of computer assisted reasoning" (McEvoy 2013, p.397). Also, the Springer Series in Computational Mathematics (n.d.), ${ }^{1}$ in its 49th volume at the time of this paper, illustrates the evolution of an established branch of theoretical mathematics, namely numerical analysis. Furthermore, the European Mathematical Society (2011) stated that "[t]ogether with theory and experimentation, a third pillar of scientific inquiry of complex systems has emerged in the form of a combination of modeling, simulation, optimization and visualization" (p.2). The notion of a third pillar had been previously raised in a 2005 report by the US Presidential Information Advisory Committee (2005) highlighting the role of digital technology: "Together with theory and experimentation, computational science now constitutes the 'third pillar' of scientific inquiry, enabling researchers to build and test models of complex phenomena" (p.1). Arguably, this pillar of scientific inquiry is founded upon computer programming or based on some form of digital technology, but is definitely not exclusively as a pencil-and-paper activity.

In our study, we view the third pillar of scientific inquiry as a rapidly developing domain of mathematics that is closely intertwined with the evolution of programmable technology. Modelling and simulation involve acceptable and sufficient mathematical descriptions of the complex system under consideration. These descriptions predominantly arise from the first and second pillars, namely theory and experimentation. In the third pillar these are combined with (interactive, dynamic) visualization and optimization, which arise as a result or part of the modelling and simulation process. The weather prediction as seen on television broadcasts is an example of an application of the third pillar. Wikipedia expresses it in layman's terms:

Numerical weather prediction (n.d.) uses mathematical models of the atmosphere and oceans to predict the weather based on current weather conditions. Though first attempted in the 1920s, it was not until the advent of computer simulation in the 1950 s that numerical weather predictions produced realistic results.

The weather models are optimised either for global or local predictions and selected visualization is projected on the screens.

The third pillar of scientific inquiry calls for a shift in university programs to integrate computer programming. Few undergraduate mathematics programs appear to have addressed this latter 21 st century scientific practice and adapted some curricula through which their students could learn to use computer programming for mathematical investigation, exploration, visualization, simulation, and real-world modelling. An exception is the interdisciplinary Mathematical and Computational Science Program at Stanford University (USA). Hoyles and Noss (2008) have noted that incorporating digital technologies, including programming, in programs for learning mathematics brings to the forefront a number of questions:

particularly those concerned with transformation of the what of mathematics rather than merely the how - precisely because digital technologies disrupt many taken-for-granted aspects of what it means to think, explain and prove mathematically and to express relationships in different ways (p.87).

\footnotetext{
$\overline{{ }^{1} \mathrm{http}: / / \mathrm{www} . \text { springer.com/series/797 }}$
} 
In our work, we focus on the incorporation of technology (specifically, computer programming) in mathematics learning at undergraduate level and we are interested in addressing some of the questions emerging from that. For example, based on insightful reflections related to our innovative integration of programming in three sequential undergraduate mathematics courses at our institution, we have discussed the issue of balancing students' learning of programming with their mathematical learning in course design (Buteau and Muller 2014). We argue that the overall aim of the course sequence aligns with a goal of developing students' proficiency (a term we define further below) in the third pillar of scientific inquiry. Indeed, an official unpublished departmental document that led to the adoption, in the year 2000, of the course sequence by the Department of Mathematics and Statistics at Brock University (Ralph 2001), states: "To encourage creativity, the three ... courses will challenge students with difficult projects that require them to develop their own strategies for handling complex real world mathematics problems" (Buteau et al. 2015, pp.141-2). This statement was supplemented with a detailed list of planned computer program assignments aligned with mathematical topics; for example, primality of a positive integer, discrete dynamical systems, etc. It was thereafter slightly elaborated as:

[Students] will confront problems from pure and applied mathematics that require experimental and heuristic approaches. In dealing with such problems, students will be expected to develop their own strategies and make their own choices about the best combination of mathematics and computing required in finding solutions.

[The] goal is to help students build a portfolio of techniques, which they are confident in applying to a diverse range of mathematical problems that may or may not have exact solution (Buteau et al. 2015, p.142).

The goal of the course sequence can be interpreted as helping students develop proficiency - which we understand as a combination of fluency and confidence - in engaging, in the third pillar of scientific inquiry, across various situations. This leads to a pragmatic question, one underlying our work, about whether students who take part in undergraduate programs integrating computer programming for mathematics learning develop proficiency in the third pillar of scientific inquiry.

Learning mathematics through an activity that engages students in computer programming is often associated with constructionism, an approach that is characterised as "unique in its attention to the ways in which meanings are generated during individual and collective bricolage with digital artefacts, influenced by negotiated changes students make to these artefacts and giving emphasis to ownership and production" (Kynigos 2012, p.1). An example in the literature of such a constructionist activity at university level for mathematical learning, is that of a student who, in a design setting, used and modified the code of a computer environment in order to understand Bertrand's paradox (Wilensky 1995).

We consider our work as also framed by a constructionism approach. Although the three-course sequence was initially developed (and implemented) independently from the constructionism literature, analysis of the learning environment of the course sequence 
shows that it promotes students' engagement in constructionist experiences for learning mathematics (Buteau et al. 2015). However, we have yet to examine in detail the constructionist character of students' mathematics learning experiences in these courses. In fact, integrating programming in mathematics classrooms does not necessarily lead to intended results, or in particular to students' constructionist engagement. For example, Misfeldt and Ejsing-Duun (2015) recall the disappointing results in the 80s and 90s of the mainstream implementation of the programming language LOGO in schools: "for instance, students easily overlook the nuggets of mathematical knowledge (Hoyles and Noss 1992b; Ainley et al. 2006), making their work [in the programming-based environment] non-mathematical" (p.3). This leads to a second question, underlying our work, about the ways in which students, who take part in undergraduate (mathematics) programs that incorporate computer programming-based tasks, engage in constructionist experiences.

This paper ${ }^{2}$ describes a naturalistic case study of an undergraduate mathematics student enrolled in our courses, in which we explore the constructionist character of her mathematics learning experiences and whether she developed proficiency in the third pillar of scientific inquiry. Our study differs from most mathematics education studies about, or framed in, constructionism in two main aspects. First, the data does not come from a research site in which the tasks and pedagogical strategies have specifically been developed for the purpose of the research, instead it is from real classroom implementations sustained since 2001 (and free from educational research purposes); for example, the 2015-16 cohort consists of 69 students. Second, our study does not investigate in depth a student's engagement in a single computer-based mathematical task or short-term sequence of tasks, but rather examines the overall mathematical work through 14 different computer-based mathematics projects over 16 months. Therefore, our case study is a post-analysis that focuses on the following questions: $i$ ) What kind of mathematical experiences did the student's overall engagement in these projects provide? ii) Was this engagement constructionist? And iii) Did the student develop some proficiency in the third pillar of scientific inquiry? In what follows, we present the theoretical framework of our study. We then describe the case study in Section "The Case Study", including a documentation of the student's overall programing-based work over 16 months, discussing her learning experiences in Section "The Learning Experience of the Student - Discussion", and concluding the paper in Section "Conclusion".

\section{Theoretical Framework}

In addition to a constructionism approach for the classroom implementation of programming, our study is also framed by an instrumental approach to address a student's appropriation of programming as a tool for engagement in the third pillar of scientific inquiry (which we will associate with 'proficiency' - see the end of this section).

\section{On Constructionism}

Constructionism is defined by Papert (1991) in the following way:

\footnotetext{
${ }^{2}$ This paper elaborates the work presented at Constructionism and Creativity 2014 conference: (Buteau et al. 2014).
} 
Constructionism - the $\mathrm{N}$ word as opposed to the V word - shares constructivism's connotation of learning as 'building knowledge structures' irrespective of the circumstances of the learning. It then adds the idea that this happens especially felicitously in a context where the learner is consciously engaged in constructing a public entity, whether it's a sand castle on the beach or a theory of the universe (p. 1).

In (Buteau et al. 2015) we describe that this implies that the basic principles of the constructionist paradigm involve learning situations or environments that are studentcentred, where students build or construct shareable objects that are somehow 'tangible' (Papert 1990). In other words, it involves 'learning through making' (Papert 1991), where the learner needs to be 'consciously engaged' in the construction, that is the learner must be reflective of his/her construction work. Another key characteristic defining constructionism is engaging in meaningful projects: "people construct new knowledge with particular effectiveness when they are engaged in constructing personally meaningful products... [that is] something meaningful to themselves and to others around them" (Kafai and Resnick 1996, p. 214).

Constructionist situations often involve open projects, generally computer-based ones (Papert 1991) such as computer microworlds. For Papert (1980b) microworlds involve objects "to think with" and "allow a human learner to exercise particular powerful ideas or intellectual skills" (p. 204) through exploration and discovery in a knowledge domain. The idea of students engaging in "powerful ideas" is a key characteristic of constructionism and is related to giving students a sense of empowerment (Papert 1996). For example, Papert (1980a) illustrates this characteristic in the context of Turtle geometry: "[e]ach new idea in Turtle geometry opened new possibilities for action and could therefore be experienced as a source of personal power" (Papert 1980a, p. 129). This stresses, in particular, what has been called epistemological empowerment, which is described as “the individual's growth of confidence not only in using mathematics, but also a personal sense of power over the creation and validation of knowledge" (Ernest 2002, p.2). A learner is in this sense empowered when s/he "can combine intuition and the procedures and skills of mathematics to make sense of the world and confidently apply mathematical thinking to it" (Ernest 2002, p.12).

The concept of microworld has evolved over time (Healy and Kynigos 2010), and a more recent definition is provided by Mavrikis et al.'s (2008) study:

[m]athematical microworlds belong to a particular genre of exploratory learning environments (ELEs) that allow students to explore not only the structure of accessible objects in the environment, but also construct their own objects and explore the mathematical relationships between and within the objects, as well as the representations that make them accessible (p.41).

Initially the focus on microworld was on the digital object, but it became obvious that it makes "more sense to discuss the term in association with the kinds of activity emerging from the use of microworlds and the scope of each microworld with respect to the conceptual field it was designed to embody" (Healy and Kynigos 2010, as reported by Kynigos 2012, [p.4]). It is in this latter sense that we shall use the term microworld. 


\section{Instrumental Genesis and Appropriation}

A useful framework for analysing technological integration (Artigue 2002; Guin and Trouche 1999) is the instrumental approach (Rabardel 1995/2002), which has begun to be used increasingly at the university level (for example, Gueudet et al. 2014). It can be useful for gaining insights into how students appropriate a (technological) tool and turn it into an instrument. According to Cook et al. (2002), appropriation is a developmental process involving socially formulated, goal-directed, and tool-mediated actions through which learners actively adopt (that is what we could call "make their own") conceptual and practical tools, thus internalizing ways of thinking related to specific settings in which learning takes place. The instrumental approach describes how artefacts (whether material or symbolic) can be transformed into instruments through schemes of usage and action by what is called instrumental genesis, and thus appropriated (Artigue 2002). Trouche and Drijvers (2010) suggest that an instrument has been appropriated when a "meaningful relationship exists between the artifact and the user for a specific type of task" (p. 673).

When examining students' instrumental genesis, it is necessary to look at both the artefact and its attached schemes. This can be carried out in part through traces that students leave in their activity of working with an artefact, that is, what they do with the artefact (Trouche 2004). On the other hand, it is impossible to consider students' appropriations and instrumental geneses without also taking into account the teacher's conceptions, design, and orchestrations of the teaching resources (Trouche 2004). One aspect in this regard is that of the concept of instrumental integration: "a means to describe how teachers organise the conditions for instrumental genesis of the technology proposed to the students and to what extent (s)he fosters mathematics learning through instrumental genesis" (Goos and Soury-Lavergne 2010, p. 313). Instrumental integration describes four stages of growing technology use in the classroom (Assude 2007): (a) instrumental initiation (stage 1) - students engage only in learning how to use the technology; (b) instrumental exploration (stage 2)-mathematics problems motivate students to further learn to use the technology; (c) instrumental reinforcement (stage 3)-students solve mathematics problems with the technology, but must extend their technology skills; and (d) instrumental symbiosis (stage 4)-students' fluency with technology scaffolds the mathematical task resulting in an improvement of both the students' technology skills and their mathematical understanding.

\section{Constructionism and Microworlds in the Light of Instrumental Integration}

Related to the growth of a student's mathematical knowledge within a computer-based microworld, Noss and Hoyles (1996) stress that a learner articulates relationships between concepts involved in a microworld "and it is in this process of articulation that a learner can create mathematics and simultaneously reveal this act of creation to an observer" (p. 54). But it is not only the mathematical knowledge that grows; there is also a change in how the concepts and tools of a microworld are used and conceived. In this respect, Hoyles (1993, quoted by Healy and Kynigos 2010) explains that "microworld grows along with the knowledge of its users" with Healy and Kynigos (2010) stressing that "it is in the growth that we can locate the essence of constructionism" (p. 65). We consider that the initial growth of the (mathematical) 
knowledge of the user, together with that of the microworld, correspond mainly to stages 2 to 4 above of the instrumental integration. And it is in stage 4 where we argue that the student has appropriated the microworld. This highlights how our two theoretical frames come together. Whereas constructionism can be categorised as a 'framework for actions' (Hoyles and Noss 2014) that, for example, prescribes characteristics for the learning environment implementation (in other words, characteristics of a student's learning experience), the instrumental integration describes different stages in implementation aiming at prompting learners to progress with their appropriation of a tool (in other words, stages of a student's instrumental genesis development).

In our case study, we analyse a student's experiences during her mathematical programming-based tasks from the constructionist perspective, as well as explore the student's proficiency by examining if she was able to appropriate programming as a tool and perhaps instrument (as articulated by the instrumental approach) for engagement in the third pillar of scientific inquiry.

\section{The Case Study}

The case study research design and methods are suitable for our study since (i) we don't manipulate the behaviour of those involved in the study (this is in fact a naturalistic study); and (ii) we want to cover contextual conditions (constructionist learning environment) because we view them as relevant to the student's mathematics learning and development of proficiency in the third pillar under study (Yin 2003).

\section{Context}

The context of our case study takes place in the Department of Mathematics and Statistics at Brock University which adapted its core undergraduate curriculum in 2001 to integrate a sequence of three innovative, core, project-based courses called MICA, an acronym for Mathematics Integrated with Computers and Applications (Ben-El-Mechaiekh et al. 2007; Ralph 2001). In these courses, all mathematics majors and future teachers learn to design, program (in vb.net), and use interactive and dynamic computer environments, which we have called exploratory objects (EOs), to investigate mathematics concepts, conjectures, theorems, or real-world applications (Muller et al. 2009). Every week students meet for a 2-h computer lab and a 2-h lecture where they progressively engage in learning and doing mathematics by creating and using their own EOs (Buteau and Muller 2014), which we recently identified as microworld-type environments (Marshall and Buteau 2014). Over the course of the MICA I-II courses, students create 14 EO projects; 11 on topics selected by the instructor, and the remaining 3, at the end of each term, on topics selected by the students, either individually or in pairs. Each EO project contains not only the interactive environment, but also a written (that is, a type of scientific lab) report. They are mostly completed outside classroom time. In their first year, all students are required to complete a Calculus and a Linear Algebra course in the Fall term followed by the MICA I course and a second Calculus course during the Winter term. In their second year, students enrol in the required multi-variable Calculus, Differential 
Equation, Statistics, Probability, and Linear Algebra courses, as well as in the twosemester MICA II course.

\section{The Subjects}

In order to illustrate the constructionist and appropriation processes that students go through by engaging in the assignments for the MICA courses, we focus here on the case study of a student, Ramona. We selected Ramona Rat for our case study based on the recommendation of one of the MICA II instructors. ${ }^{3}$ Ramona enrolled in 2011 in the MICA/Co-op program with a concentration in Statistics, a 5-year program. Prior to MICA I she had had no programming experience, which is the case for most MICA I students. Ramona is among our top students with an overall average of $94 \%$ for her undergraduate studies. At the time of the data collection, she had completed her MICA I-II courses and was enrolled in her fourth year.

In addition to focusing on Ramona, we complement the analysis of her work with some data from the comments to post-questionnaires (see below) of two other students from different mathematics concentrations (whom we shall call Martin and John); this provides us with complementary data on students' learning experience through their 14 EO projects. Martin is a fourth-year student in the mathematics education concentration who partnered with Ramona for the MICA II original projects (EO 9, EO 14). John is a graduate student from the pure mathematics concentration and teaching assistant of MICA I during Winter 2014. Both Martin and John had no programming background prior to enrolling in the MICA I course. Data from these two students were used to compare and complement the case study analysis by providing different perspectives.

\section{Data Collection and Analysis}

In the Spring of 2014, we collected Ramona's 14 EO projects, directly from her, together with their related written reports (digital versions) as part of her MICA I-II course load during Winter 2011 and Fall 2011-Winter 2012. In addition, Ramona provided us with a copy of her MICA II lecture notes (we had no need for MICA I lecture notes due to our involvement in teaching and analysing the course in past publications). We also collected all of the 11 assignment guidelines, from the MICA I-II instructors. Using the lecture notes and the assignment guidelines as context, we examined Ramona's EOs and related reports in order to describe Ramona's mathematical EO work over 16 months. At times in her written reports, Ramona had voluntarily inserted reflections on her learning experience through the projects. These provided insights into her learning experience as she was going through the MICA courses. In some sense, these reflections revealed information about Ramona's design process of certain EOs which complemented the 'final products', that are the submitted EO environments. Excerpts of these reflections had been carefully added to the mathematical work description. All together, the EOs and related written reports provided a trace

\footnotetext{
${ }^{3}$ The MICA II instructor's recommendation was mainly based on Ramona's volunteer participation in promoting in different venues the MICA program to potential students and at which she had been showing some of her own MICA projects. We use Ramona's real name in this paper; it had already been used in Buteau et al. (2014).
} 
or snapshot of Ramona's mathematical learning experience as she engaged in creating and using EOs for mathematical investigations.

In order to get more insights into Ramona's learning experience, we also created a questionnaire (see Appendix I) that aimed at investigating, a posteriori, specific characteristics of a student's potential constructionist experience. Ramona answered the questionnaire in Winter 2015, and so did Martin and John.

Ramona's mathematical work documentation and the three participants' questionnaire were carefully examined and coded according to concepts of constructionism and stage 4 (instrumental symbiosis) of instrumental integration (which we associated with appropriation of programming). In the analysis, we consider programming in Visual Studio as a microworld tool, that is the vb.net programming language in the development environment Visual Studio, together with the learner's use of engaging in the third pillar of scientific inquiry. In this exploratory study, we do not aim at examining Ramona's instrumental genesis of programming, nor real-time process of learning, but rather at investigating the outcome of Ramona's instrumental genesis development progress: mainly, has she or has she not appropriated programming as an instrument for the third pillar of scientific inquiry.

\section{Case Study: Ramona's Fourteen Mathematical Programming-Based Projects}

The following provides documentation of Ramona's overall mathematical exploratory object work (EO 1 to EO 14) in first-year MICA I (Y1 below) and second-year MICA II (Y2 below) courses. The mathematical work in each EO involves two facets: at first, students program mathematics that has been covered during their lectures, and second, students use their EO program to explore mathematics that initially is unknown to them (through an experimental mathematics approach). For example, in EO 3 (below), students learn about dynamical systems and cobweb diagrams during lectures which they then need to program to explore their specific behaviour unknown to them. In some cases, for example in EO 5 (below), students are also required to develop the model under investigation, and as such, need not only explore but also program mathematics not covered in lectures.

Y1-EO 1 As part of the first MICA I lectures, students are guided to conjecture about prime numbers and Hailstone sequences, while in their lab sessions they learn first basic concepts of vb.net programming in Visual Studio (design interfaces, programming variables, loops, and decision structures). The first EO assignment is to select or state a conjecture, and to create and use their EO to explore it.

Ramona selected Oppermann's conjecture that states for any integer $n>1$, there is at least one prime number between $n(n-1)$ and $n^{2}$ and at least another prime number between $n^{2}$ and $n(n+1)$. Ramona indicates in her written report:

I wanted to select a conjecture that genuinely interested me, so I selected this one. I thought it was interesting how such a simple process could potentially work for every single integer greater than one, and I wanted to see the legitimacy of the conjecture for myself by using this opportunity of writing a program. 
Using her very first self-created EO (Fig. 1, left), she concluded in her EO written report, that

[w]hile I was inputting various integers and confirming them, I became more and more surprised that this idea is still a conjecture and not yet a theorem. Even though there is still no proof of it up to this day, my sample data has proven to me that Oppermann's conjecture is a great idea, seeing as how I, personally, believe it works.

She also indicated that learning about this new conjecture about primes led her to learn more about prime numbers themselves.

Y1-EO 2 Students learn about modular arithmetic, leading to contemporary RSA encryption, a method used for secure data transmission based on the virtual impossibility to factor the product of two very large prime numbers. It involves a greatest common divisor (gcd) algorithm, powers and multiplicative inverses in integers modulo n, and the Euler phi function giving the number of relatively prime integers smaller than a given $\mathrm{n}$. Meanwhile in the laboratory sessions, students further their programming skills and fluency (functions and modules, and more complex mathematics programs). Their second EO assignment is to implement the RSA encryption algorithm, including encoding, decoding, and randomly generating keys.

Ramona, using her EO (Fig. 1, right), encoded and decoded her name, and described the details in her written report: with public key $(16171,19)$, her encoded name is 3447-2372-1065-1137.

Y1-EO 3 The mathematics content moves to discrete dynamical systems. With new programming skills learned (arrays, graphics), students create an EO about the logistic function $\mathrm{f}(\mathrm{x})=\mathrm{kx}(1-\mathrm{x})$ (one parameter $\mathrm{k}$ involved), and are guided by the instructor to systematically explore, graphically and numerically, its behaviour. Their third assignment is to create an EO to explore the dynamical system based on a cubic (two parameters involved), and describe its behaviour (Fig. 2, left).

Ramona (voluntary) mentions in her written report, that "[b]oth creating and working with this program has assisted me to fully grasp the way a dynamical system works by observing the table, the graphs, and the cobweb with countless test values for $\mathrm{a}, \mathrm{b}$, and $\mathrm{x}_{0} . "$

Y1-EO/LO 4 (Original) The MICA I-II courses both culminate at the end of the term in original final projects for which students, individually or in groups of 2 or 3 , choose

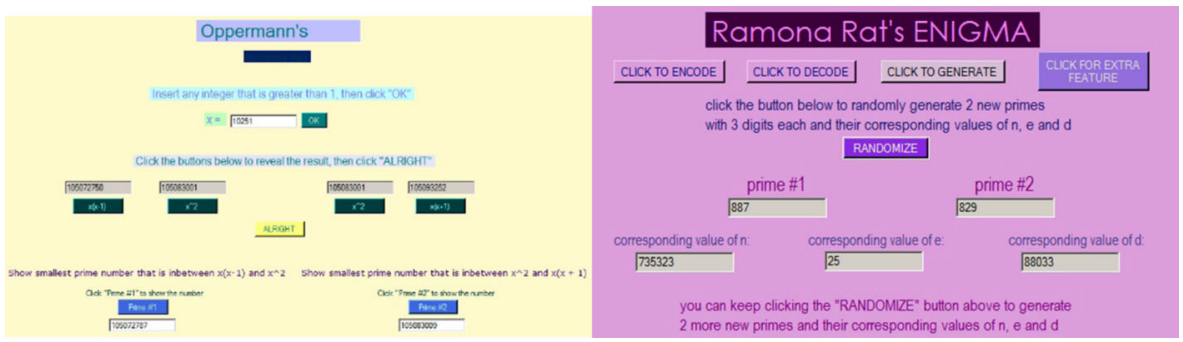

Fig. 1 Ramona's first EO (left) and second EO (right) 

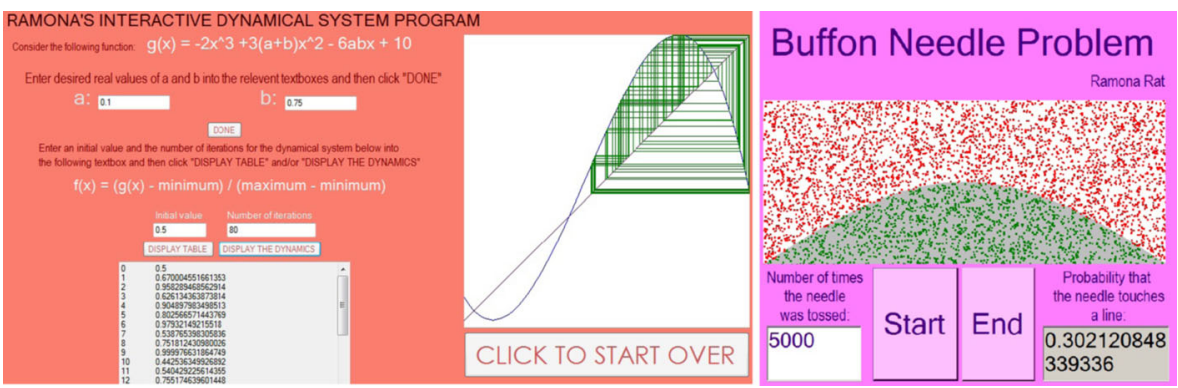

Fig. 2 Ramona's third EO (left) and fifth EO (right)

a topic of their own choice; see MICA URL (n.d.) for examples of student projects. Students are encouraged to select topics that are of high interest to them. For this final project future mathematics teachers can choose to create an environment for the stepwise guided learning of a (school) mathematical concept or skill, that we call Learning Object (Muller et al. 2009).

Ramona and her future teacher partner Carrie, decided to create a LO for Grade 4 students to learn about perimeter (Fig. 3). After observing Ramona's friend's Grade 4 younger sister going through the program, they proudly reported that, "she ended up understanding the concepts reasonably well, which makes our work feel very meaningful."

Y2-EO 5 The second-year MICA course starts with the Buffon needle problem that involves dropping a needle onto lined paper and determining the probability that the needle touches a line (and involves Monte Carlo integration, a numerical technique that chooses random points at which to evaluate the integrand). Students also cover the concept of randomness in programming. Their first EO assignment contains four components: i) a modified Buffon needle problem (Fig. 2, right); ii) the area of a stratified region in a rectangle; iii) the area of a unit hyper-sphere, and iv) the BuffonLaplace problem (the needle is dropped onto a square grid paper).

Using her EO for iii), Ramona wrote that, "I can confidently conclude that the estimates for the volume converges much quicker to the correct value as n gets large." Ramona described her approach to iv) with many visuals, mentioning "one must develop the formulae that can be used to calculate values ...", and after elaborating on the mathematics involving the angle of the needle to the horizontal line, she cautioned that "[h]owever, this problem isn't as simple as it looks" as her initial approach "cause[d] serious mistakes since the actual 'line hits' end up being evaluated as 'line misses' "in a specific case that she visually represented (angle between $\pi / 2$ and
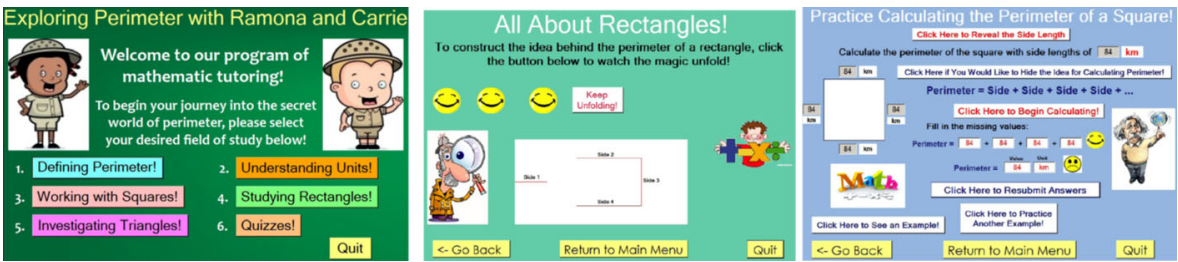

Fig. 3 Selected screen shots of Ramona's first year original Learning Object project (EO/LO 4) 
$\pi)$. She finally indicated how she then fixed her model by treating the angle of the needle in two different cases: $[0, \pi / 2]$ and $(\pi / 2, \pi]$.

Y2-EO 6 Students are introduced to the mathematics of the stock market involving many statistical concepts. Programming-wise, they learn to implement related statistical concepts, explore and experience the Central Limit Theorem, and learn to read data from files. Their assignment contains three components: i) histogram summary of (real data) S\&P 500 index ${ }^{4}$ from 1950 to 2012, and analysis; ii) statistical analysis of a selection of 10 different stocks (of their own choice), and recommendations (with justification) to a fictive client; and iii) a regression analysis of Walmart stock over a decade (Fig. 4, left).

Based on her selection of stocks, Ramona mentioned that, she "would definitely recommend a client to buy the AAPL stock since it's the most ideal choice when looking at the mean and the average yearly percentage." In her analysis of Walmart stock, Ramona indicated that,

the correlation coefficient is negative... This implies that there is both a very weak correlation (that is, a weak relationship between the current returns and the last returns) and a negative slope (of the regression line). Judging from the "cloud" that the points form, a weak correlation is correct.

Y2-EO 7 The course evolves to another real-world mathematics application: the synchronization of traffic lights. Students are exposed to modelling from the ground up using real data and a simple mathematical concept (time difference). In this 'Industrial Mathematics in the Community' EO assignment, students work in groups of 2 to 3 to collect real data at two downtown traffic lights of their choice, and create an EO to analyse and explore a proposed model of synchronization, and to propose their own.

Ramona's team described, "now that we understand this [given] definition of synchronization, we can come to the conclusion that it is possible to make a clear case that the traffic lights we selected can't be synchronized", which they then justified using their data. They further investigated the model (Fig. 4, right; for which $p=1,2,3$, ...) and stated that, "[o]ur conjecture about the relationship that must hold between $\mathrm{m}_{1}$ and $\mathrm{m}_{2}$ in order for the two traffic lights Alpha and Beta to be synchronized correctly (that is, that an optimal time occurs in each of the columns) is that $\mathrm{m}_{1}=\mathrm{m}_{2}$."

Y2-EO 8 The mathematics content covered shifts to Markov Chains which was significantly elaborated in lectures, and involves the concept of equilibrium. In their EO assignment, students apply the mathematics as a model of income demographics and chronic illness.

In the former, Ramona found that independently of the proportions in each socioeconomic category, "the equilibrium [of the given model] will always be reached." (Fig. 5, left). She also explored a modified model in which the next generation of highincome wage earners remain so.

\footnotetext{
${ }^{4}$ Wikipedia describes S\&P 500 (n.d.) as "an American stock market index based on the market capitalizations of 500 large companies having common stock listed on the [New York Stock Exchange]".
} 


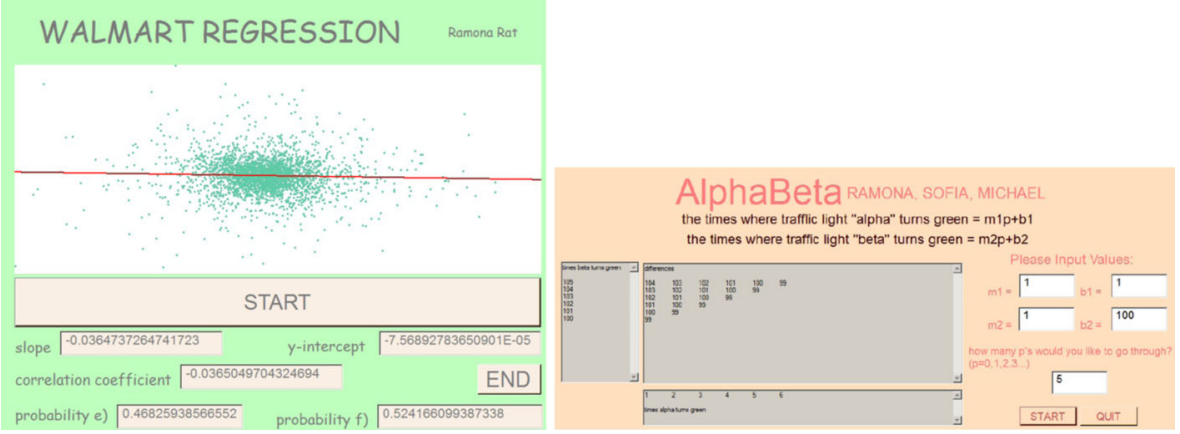

Fig. 4 Ramona's sixth EO (left) and seventh EO (right), the latter created with two partners

Y2-EO/LO 9 (Original) Ramona teamed up with two colleagues and they decided to create an EO to explore the effects of earthquakes (using the Richter scale) on buildings of different ages (i.e. exploring how many of them crash on average) (Fig. 5, right). They report, "[w]e researched some statistics on various websites about the age of buildings that crashed in order to develop the [model]" and indicated, with detailed justification, how they "treat the Richter scale ... based on [their] research". Using their EO, they explored the model they had created, and compared it to known statistics: "[t]his observation was possible based on both our research and our program." They summarised their results on the effects in table form. They added to their initial exploration, "[t]his general pattern forms several curves which we call equidamage curves. These curves display the most crucial relationship in our study, which is the relationship between the Richter Scale value ... and the value ... that determines the age distribution of the buildings in the city".

Y2-EO 10 Students revisit discrete dynamical systems in a more in-depth approach, including an analytical classification of the fixed points of the logistic function. Students create an EO to explore and analyse the bifurcation diagram (Fig. 6, left).

Following the assignment guidelines, Ramona very thoroughly analysed the system and reported her findings in her written report using numerous screenshots as support,
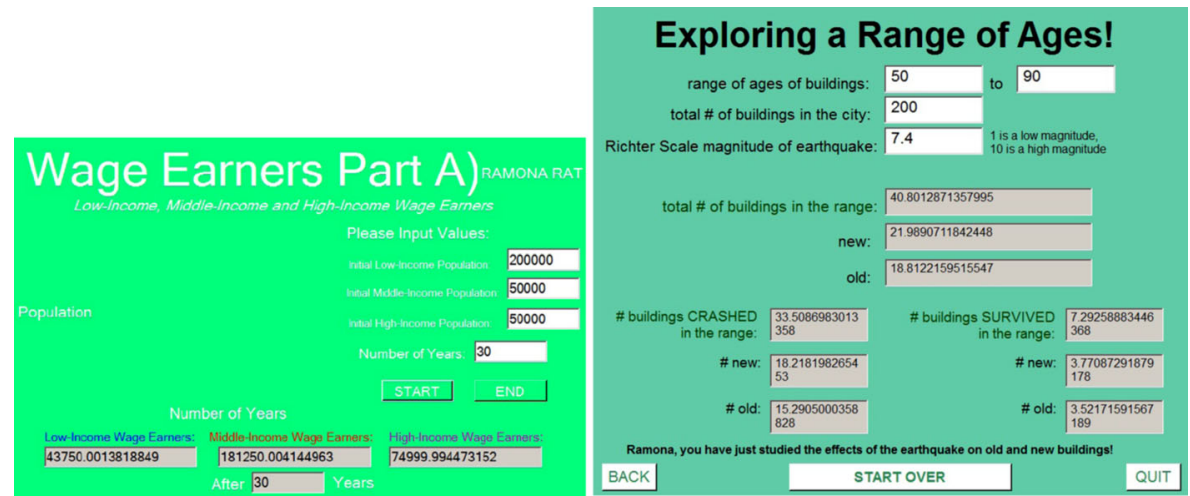

Fig. 5 Ramona's eighth EO (left) and ninth original EO (right), the latter created with two colleagues 

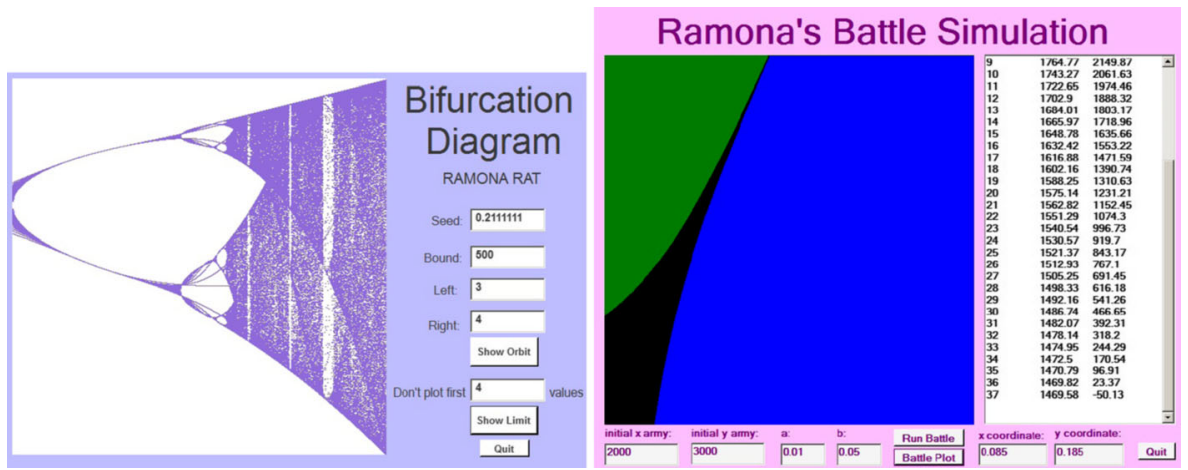

Fig. 6 Ramona's tenth EO (left) and eleventh EO (right)

complemented with Maple algebraic calculations. She observed that, "there seems to be exactly one downward sloping 'curve' that exists from the third bifurcation point ... and on. While some other 'curves' seem to appear and then fade off into the mess, this specific 'curve' seems to be consistently visible."

Y2-EO 11 Students examine the discrete Lanchester equations that simulate a battle between two armies using an analytical approach, with emphasis on interpretation. For their EO assignment, students simulate battles according to this model (Fig. 6, right), and expand it to include the exploration of random arrival of additional troops (i.e., stochastic processes).

Ramona describes, that "[o]bserving my program ..., this battle [where army X, with $5 \%$ strength, has initially 2000 troops, and army Y, with $1 \%$ strength, has initially 3000 troops] will end on the 37 th day with the $\mathrm{X}$ army winning." Discussing her exploration of the stochastic extension of the model (where new troops are arriving at random every day), Ramona brings forth different possible explanations of the model behaviour, and concludes:

My main finding ... was that it is a wasted effort to send too many new troops ... Observe the screenshot I have provided ... If one let $P=500$ instead of $P=2000$ [where $\mathrm{P}$ is the population of new troops from which a random proportion is selected daily], approximately the same probability [that the army X wins in less than 20 days] is calculated. It is a waste of funds and equipment to send so many new troops when much fewer can do roughly the same job.

Y2-EO 12 The mathematics content evolves to continuous dynamical system with a predator-prey biological model, described by the Lotka-Volterra differential equations, involving Euler's method and phase plane trajectories. Students create an EO to explore balancing this biological system (Fig. 7, left) by examining different required case scenarios.

Ramona, using her EO, explores, analyses, and interprets the behaviour of the system; for example, she states: 


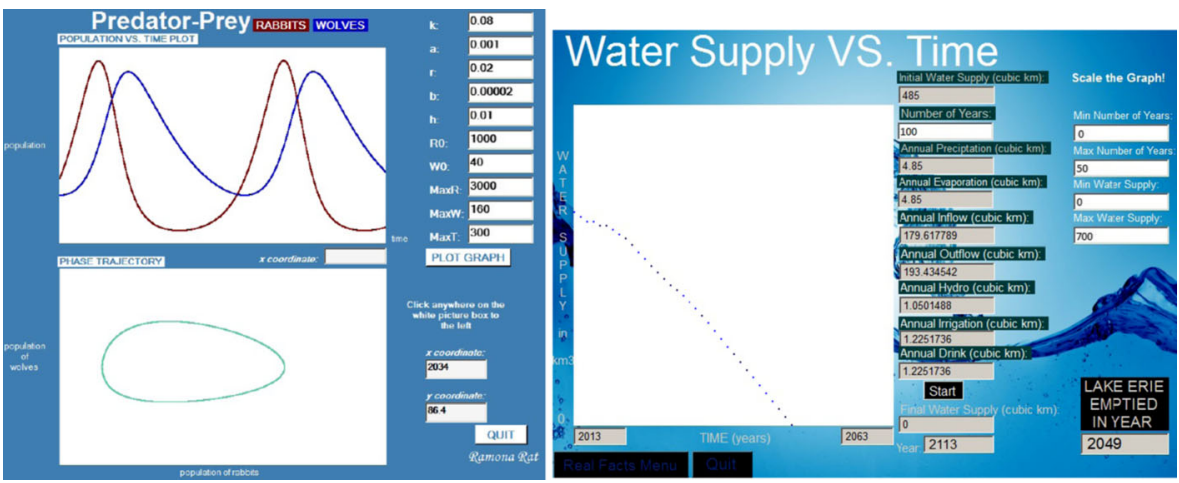

Fig. 7 Ramona's twelfth EO (left), and fourteenth original EO (right)

[t]herefore [in this case shown in Fig. 7, left], since the wolves will have more rabbits to eat due to their population increasing through reproduction, their population is expected to grow as well, which will lead to the rabbit population falling again because there are more wolves to eat them. Essentially, the cycle patterns are similar ... [as] explained through the comparison of the two screenshots.

Second-Year Student EO 13 Students are introduced to the theory of cellular automata. The EO assignments culminate, programming-wise, in this challenging EO that involves two-dimensional arrays and the process of cellular automata. Students create simulations of epidemics to examine the effects of inoculation on the spread of epidemics, and their cost.

Ramona experienced real-time simulations of required case scenarios (Fig. 8), and reported her results in her written report in terms of highest susceptible percentage. Building on a simulation of a specific epidemic (probability of infection $=10 \%$; infection duration $=10$ days; initial population infected $=1 \%$ ) and calculations of specific related costs ( $\$ 250$ to immunize a person; $\$ 30 /$ infected person for daily medical treatment), Ramona estimated the related total costs and reported that her "estimate for the percentage of immunized people that minimizes the cost of the epidemic is $67 \%$ by inspection in which the cost is $\$ 12,078,150$." She ends her report by a brief required mention of ways to improve the accuracy of her estimate: of her two suggestions, one involves running many simulations with a same initial percentage of immunized population, “[s]ince much of the program's output involves generating random values that can change each time, [so] this approach would retrieve a (potentially) more accurate result and flatten out any outliers."

Y2-EO/LO 14 (Original) For this final original project, Ramona teamed again with her two colleagues. They decided to create an EO to explore the changes in the water supply of Lake Erie (Ontario) over time and explain why and how it changes (Fig. 7, right). Their remarkable real-world EO project involved relatively comprehensive research. Indeed, they indicate that their research was "a crucial starting point in [their] project, allowing [them] to obtain an understanding for the changes in the water supply 

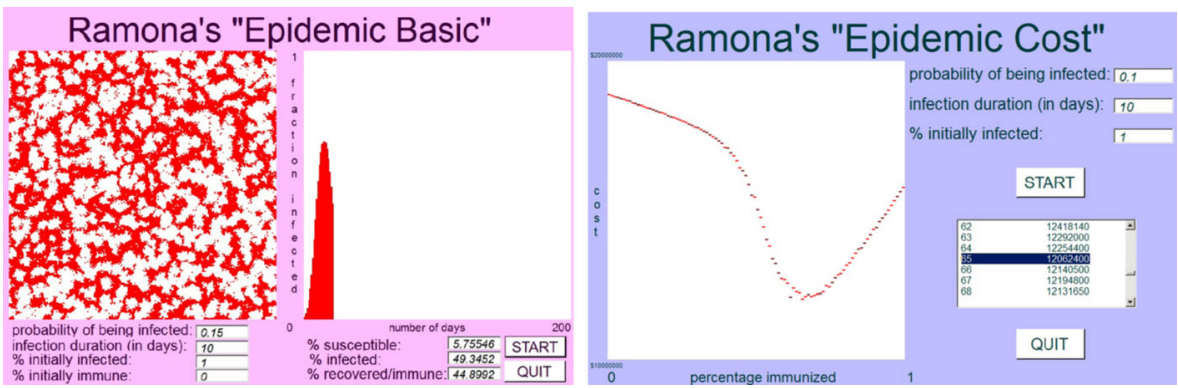

Fig. 8 Ramona's thirteenth EO (simulation of epidemic to the left, and its related cost to the right)

of Lake Erie". They also called private companies to request figures not made public on their websites. In a detailed 26-page report, they thoroughly enumerate and justify, based on their research, all numerical values and assumptions that are used in their (deterministic and stochastic) models and EO, respectively. They were careful that their models mirror reality: "[i]t was good to have a reference to make sure our calculations, assumptions, etc. were correct." They analysed six case studies, and added a 'free-will' simulation "useful for someone who is trying to save Lake Erie".

\section{The Learning Experience of the Student - Discussion}

As was illustrated in the previous section, Ramona (and all other students) in MICA courses construct (or make) and use at least 14 EOs during their undergraduate studies (Buteau et al. 2014), that are shareable digital objects. These courses aim at prompting students to reflectively engage in constructing and using mathematics exploratory objects (Buteau et al. 2015). In terms of pedagogy, the MICA instructor plays more of a facilitator role presenting situations to solicit students to think like mathematicians (Buteau and Muller 2014) - which aligns with a constructionist approach (Papert 1991; Hoyles and Noss 1992a). In this section we examine Ramona's constructionist experience of learning mathematics and explore whether she appropriated programming as an instrument for engagement in the third pillar of scientific inquiry.

\section{Mathematical Experience}

The overall description of Ramona's 14 EO mathematical work suggests that Ramona meaningfully engaged with mathematics through her MICA courses which can be seen as a significant learning experience. In fact, all EO assignments are assessed on their technological and mathematics components, including the communication of findings through the written reports, which are complemented for the MICA course final grades with mathematics content written tests. Every one of Ramona's EO projects was graded above $90 \%$, and so were her mathematics tests. ${ }^{5}$ Overall the mathematical work summarised in Section "The Case Study" suggests that Ramona's knowledge of mathematics grew over the 14 EO projects, as she engaged more and more in the

\footnotetext{
${ }_{5}^{5}$ Ethics procedure concerning publishing Ramona's grades in MICA courses was approved.
} 
programming activities; this suggests a constructionist type of learning (cf. Healy and Kynigos 2010).

Her voluntarily reflections added to her EO written reports provide more insights about her learning of mathematics through some projects. For example, Ramona seems to suggest that through constructing and using her EO for the investigation of a discrete dynamical system (EO 3), she articulated the relationships involved in the system, and as such, learned (or created) the intended mathematics (Noss and Hoyles 1996): "[b]oth creating and working with this program has assisted me to fully grasp the way a dynamical system works by observing the table, the graphs, and the cobweb with countless test values for a, $\mathrm{b}$, and $\mathrm{x}_{0}$." Ramona's reported mathematical work in her EO 5 project about the Buffon-Laplace problem suggests what Noss and Hoyles (1996) have described as a window on Ramona's learning. Indeed, Ramona's EO 5 report suggests that she engaged in articulating the relationships involved: "one must develop the formulae that can be used to calculate values ...", whereas she indicates that her initial approach "cause[d] serious mistakes", and writes how she then fixed her (mathematical and EO) model. This suggests that Ramona constructed new mathematical meanings whereby her programmed EO environment may have acted as a window on previously unnoticed relationships and structures - a window on mathematical meanings (Noss and Hoyles 1996). Overall, these two examples (EO 3 and EO 5) suggest that Ramona engaged reflectively in the construction of her mathematical EO.

In the constructionist approach found in MICA courses, programming is central to the EO activity. Looking again at Ramona's description of her experience in EO 5, her account suggests inquiry of the kind expected by young students working in LOGO: "Why doesn't this work right? How can I fix my ideas?" (Constructionism and Creativity Conference, n.d., par.6) that she then resolved in a programming context. This aligns well with Wilensky's (1995) observation of a university student's microworld experience, where he notes that, "It was not until [the student] programmed a simulation of the problem that she began to resolve [Bertrand's] paradox" (p. 272). More generally, Ramona reflects a posteriori: "In order to participate in the full learning experience, the ride must start with a blank code." And this seems to be the view of other MICA students. For example, John indicates appreciating the learning that results from programming mathematics: "I think that it was beneficial having to do things from scratch. Half the fun of programming is fixing the bugs anyway!" and "the problem solving required for fixing bugs I felt improved my logic skills in general". Also, Martin does not seem to appreciate less the learning resulting from programming mathematics:

I am a strong believer in learning through discovery and creating your own individual method to attaining knowledge. I think by creating your own program and discovering the solution to the problem through your own method allows for a more in-depth understanding of the system.

Furthermore, reflecting a posteriori about her overall MICA experience, Ramona suggests that, through programming, the articulation of relationships between 
mathematical concepts needed in the construction of her EOs provided her with a deep understanding of the mathematics involved:

The main standout between the assignments given in the MICA courses and those given in other math courses is the ability to have the related concepts permanently embedded in your brain. I believe this embedding occurs because we write codes to solve the problems from scratch. If I had not built the programs on my own, I would not understand the way that they work.

In the same vein, Martin indicates,

I do not believe the knowledge of the [mathematical model] will stick with [students] as much as it would if they were the sole creator of their program and discovered the knowledge through their own process. I think in either case the analysis of the [mathematical model] will occur, but through creating your own project, the understanding and retention of knowledge will/could be higher.

\section{Constructionist Experience}

Ramona's mathematics learning experience was shaped by her engagement in the creation (from scratch) and use of her 14 programming-based mathematics EO projects, which is often associated to a constructionist type of learning (cf. Healy and Kynigos 2010). A key principle in constructionism is to engage students in meaningful projects. Right from her first microworld experience (EO 1), Ramona reports engaging in such a meaningful project: "I wanted to select a conjecture that genuinely interested me". She also a posteriori indicates that her last two original projects (EO 9 and EO 14) "were inspired by [her] interest in nature", and that, in relation to some of the assigned EO projects: "[a]ll of the mathematics explored (RSA encryption [EO 2], the bifurcation diagrams [EO 10], the Lotka-Volterra equation [EO 12], etc.) were both meaningful and memorable to [her]." And this key constructionism principle seems to pertain to other MICA students. Indeed, Martin explicitly mentions: "These [MICA] courses also offer the chance for students to create their own projects and explore new systems of either personal interest or popular to the world."He also indicates about his EO 13 assignment that, "the strong connection with the project and the real world made it even more interesting to me“" When describing about his own experience, Martin indicates that he viewed his original projects meaningful to others; for example, about the earthquake EO 9 project with Ramona: "At the time I thought that such a program would have a huge aid in certain areas of the world that suffer from many earthquakes" and about the Lake Erie EO 14: "I found this project particularly interesting as it is directly related to a problem occurring at present day." And so it was for John, who states: "the fact that I had come up with [the topic of my original project EO9] myself made a difference". When asked about an example of mathematics that he did in MICA courses and found meaningful to him, he answered, "[t]he assignments", suggesting the way that mathematics was learned in the course made it meaningful. Furthermore, Martin viewed his war simulation project (EO 11) "fascinating to many people who aren't even 
mathematicians... [since] the Lanchester Degree model...is actually used at an institution in the United States that focuses on the analysis and simulation of wars".

The latter constructionist principle possibly contributed a sense of ownership and pride that led Ramona to show almost all of her EO projects to her family and friends. Interestingly without any knowledge of Papert's work, Ramona noted": "In the same way that art students have their artwork to bring home, students in MICA have impressive computer programs to bring home." Martin also indicated that he "show[s] many of [his] projects to people". As for John, he did not show his projects to others, except for the written report of one of his MICA II original projects that he showed to a friend since "he had made a [related] comment ... that [John] didn't think was quite right."

Connected to constructionism is the idea of empowerment. Already at her first EO project (EO 1), Ramona voluntarily comments in her written report: "I wanted to see the legitimacy of the conjecture for myself by using this opportunity of writing a program". This shows her confidence in creating an environment to validate for 'herself' the conjecture, suggesting that she was not looking for an external authority and as such, was geared towards "a personal sense of power over the creation and validation of knowledge" (Ernest 2002, p.2). Despite having no programming background when starting MICA I course, Ramona seemed to grasp right away how programming could assist her in learning mathematics. This sense of epistemological empowerment is also experienced by other MICA students. For example, when reflecting about the specific role of coding in his learning experience, Martin points to a sense of power over the creation of mathematics knowledge: "I think another major component to discovering the code on my own is the knowledge I have developed about how to creatively think about a problem for ways that it could be modelled." As for John, he elaborates in broader terms when comparing with his other mathematics courses: "For other courses, it was more about applying theorems to solve problems: here we start with the problem and figure out our own way of solving the problem."

\section{Proficiency in the Third Pillar of Scientific Inquiry}

Ultimately, as indicated in the introduction, the constructionist MICA implementation aims at developing students' proficiency in the third pillar of scientific inquiry in the sense of students appropriating programming (viewed as a microworld tool). The sequence of MICA courses could be described as being used to prepare students for their original EO projects (EO 4, 9, \& 14) (Buteau et al. 2014). These provide an opportunity for students to engage, through programming, in the third pillar of scientific inquiry starting at its very first step, namely raising a question, identifying a problem, choosing a situation to model, etc., followed by modelling, simulating, and visualising. We argue that Ramona's EO 9 and EO 14 work suggest that she engaged in the third pillar of scientific inquiry. Indeed in both EO cases, the written report suggests

\footnotetext{
${ }^{6}$ When following up with Ramona on whether this comparison to art students was something she had read or heard about, she answered: "I took an art course in the 9th grade and my room is filled with paintings I did during that time. I made the comparison as I was filling out the questionnaire in my room."
} 
that Ramona and her two partners engaged in mathematical research supported by programming that we connect to the stage of instrumental symbiosis, that is, instrumental integration (Assude 2007): they indicated researching the web for facts and data which they used to create, program, and validate their models (modelling), and they summarised the key relationships found in their research (for example from simulation and visualisation), including naming curves, for example. In particular, they seem to have individually developed a meaningful relationship with programming for engagement in the third pillar of scientific inquiry, and could thus have appropriated programming as an instrument (cf. Trouche and Drijvers 2010). Furthermore, this suggests Ramona and her two partners' fluency with programming where it seems to have been used simply as a means in their mathematical work. In addition, Ramona states $a$ posteriori: "[my EO9 and EO14 original projects] were inspired by my interest in nature which was developed over the course of my university career through completing various chemistry and biotechnology courses", suggesting that she had the confidence to engage in an EO work personally meaningful to her. In other words, Ramona's programming knowledge and skills do not seem to have limited her at the time when deciding on the topics for her original projects.

But beyond her work, Ramona also explicitly suggests that the MICA courses aimed at developing her confidence and fluency in using programming to engage in the third pillar of scientific inquiry: "The MICA I-II courses not only teach you how to solve various mathematics problems by hand but also teach you the modern and real world approach of solving those same problems via computer [programming]." This seems to be the view of other MICA students. For example, Martin describes his view about the aim of MICA courses:

MICA ultimately is the gateway to the future of math and the world, in my opinion. The connection between powerful computer software and the complexity of mathematical systems allows for the exploration of almost any living or theoretical system in the world.

Martin's reflection suggests that he actually appropriated programming for the third pillar of scientific inquiry: "many people have found it fascinating how I have been able to take math equations and calculations and turn them into working models that simulate such complex and interesting real world applications." He further elaborates in a way which seems to point not only to a state of instrumental symbiosis with programming, but also to a sense of epistemological empowerment:

In almost any scenario, the creation of a mathematical model on a computer program can be made to simulate, test, explore or discover any dynamical system... MICA has opened my learning pathway to explore the possibility of being able to create models for major companies to be used for research purposes... The possibilities are only limited to the creativity of the mathematician making the models. I think the major skill I will take with me from MICA courses is the ability to create, analyse and explore dynamical systems and make the connections between them and the real world. 


\section{Conclusion}

In the programming-based mathematics MICA courses, students such as Ramona engage in constructionist experiences of mathematics learning. For example, Ramona engaged reflectively in constructing and using her mathematical interactive computer environments (for example, EO 3), which she indicates provided her with a deep understanding and greater retention of the mathematics involved. Students also progressively develop proficiency in the third pillar of scientific inquiry mentioned by the European Mathematical Society (2011). For example, Ramona and her two partners identified a realworld situation of great interest to them, namely the issue of the decreasing water level of the nearby Lake Erie (EO 14), and engaged in researching, modelling, and simulating various scenarios in order to explore different solutions. They thereby demonstrated their confidence and ability to engage, through programming, in the third pillar of scientific inquiry.

The design of the MICA courses can be seen to provide a sequence of 11 stepping stones to guide the student's learning of programming as a tool within a context of increasingly complex mathematical ideas identified in the third pillar of scientific inquiry. In the first-year course students learn about this approach of doing and learning mathematics, including learning computer programming, in an accessible mathematics context (Buteau and Muller 2014). For example, Ramona attended her first MICA course with no prior background in programming, but after 4 weeks designed and programmed her first EO to explore Oppermann's conjecture about prime numbers (EO 1). In the secondyear course, the focus evolves towards applying the approach with more advanced mathematics. For example, Ramona programmed as her last assigned EO (13) project a real-time simulation of epidemics based on cellular automata, and explored both their evolution and their related approximate costs for immunization. In the design of the 14 EO sequence the original three EO projects (EOs 4,9,14) on topics selected by an individual, or pairs of students, take on a central role. As exemplified by Ramona's EO 14, these three original projects are more demanding and personal than the 11 assigned EO projects. We argue that they can be regarded as milestones where students are able to demonstrate their ability to engage in the third pillar of scientific inquiry on a topic of their choice. However some students find the MICA courses very challenging, and thereby do not reach the level of proficiency that Ramona did.

Healy and Kynigos (2010) indicate that, "a criticism that can be levelled at studies investigating microworld use is that the complexities associated with the appropriation by the user of microworld tools have not always been given adequate attention" (p. 66). In our case study, we examined a student's sequence of programming projects in their final form and her a posteriori reflections of her learning experience in order to explore whether or not she appropriated programming for engagement in the third pillar of scientific inquiry. Building on this case study, our future research will aim to examine how the transformation of programming into an instrument happens. It will involve, not only students like Ramona who successfully come to reach a proficiency in using programming for engagement in the third pillar of scientific inquiry, but also those whose instrumental genesis development progresses much slower. 
Papert (1980a) in his book Mindstorms proposes that microworlds should provide a "growing place" where individuals engage in powerful ideas. He writes:

The Turtle World was a microworld, a "place," a "province of Mathland," where certain kinds of mathematical thinking could hatch and grow with particular ease. The microworld was an incubator...The design of the microworld makes it a "growing place" for a specific species of powerful ideas or intellectual structures (Papert 1980a, p.125).

As we reported in Section "The Learning Experience of the Student Discussion", Martin mentions that through the 14 programming-based mathematical tasks he has developed the knowledge "about how to creatively think about a problem for ways that it could be modelled." We argue that it is this students' sense of empowerment which the case study suggests that is connected to the powerful idea discussed in this paper, namely, the third pillar of scientific inquiry.

Acknowledgments Our sincere thanks to Ramona for her great generosity to share with us about her experiences in MICA courses.

\section{Compliance with ethical standards}

Conflict of Interest The authors declare that they have no conflict of interest.

\section{Appendix I}

\section{Questionnaire used for students' a posteriori reflections on their MATH experiences Name:}

Program of Study:

Concentration(s) (if any):

Career plans (if any):

In the following, please answer as many questions as possible. There is no right or wrong answer: it is all about your own experience within your undergraduate mathematics education, particularly in your MATH I-II courses.

- How would you describe the MATH I-II courses to a mathematics undergraduate from McMaster University?

- What do you feel you have learned from your MATH I-II courses? Describe.

- Contrast what you've learned in MATH courses versus what you've learned in your other math courses in terms of skills and competencies, i.e. not in terms of specific math content.

- Contrast what you feel you experienced in MATH courses versus what you experienced in your other math courses in terms of your personal and/or mathematical interests.

- Briefly describe the topic of each of your three final projects in MATH courses, and how you came to choose each of the topics.

- Which of the MATH topic(s), assignment(s) and/or final project(s) was/were your favorite and why?

- Have you shown any of your completed MATH projects (assignments and/or final projects) to someone? If so, which one(s), to whom, and why? 
- Give an example of some mathematics that you did and found 'meaningful to you' in:

- MATH I-II courses;

- another mathematics course

- $\quad$ a course outside the math department (if applicable)?

- $\quad$ Put yourself back into your MATH II course (after you've done MATH I course). Suppose at the time you had been given the codes, and had only to create interfaces and possibly slightly amend the codes for your mathematical investigations. Do you think your learning would have been the same? Explain.

- $\quad$ Put yourself back into your MATH I-II courses. Suppose at the time you would have received complete executable files for each assignment, and suppose you would have been asked to only use them for your assignments (no possibility to modify). Do you think your learning experience would have been the same? Explain.

\section{References}

Ainley, J., Pratt, D., \& Hansen, A. (2006). Connecting engagement and focus in pedagogic task design. British Educational Research Journal, 32(1), 23-38.

Artigue, M. (2002). Learning mathematics in a CAS environment: the genesis of a reflection about instrumentation and the dialectics between technical and conceptual work. International Journal of Computers for Mathematical Learning, 7(3), 245-274.

Assude, T. (2007). Teachers' practices and degree of ICT integration. In D. Pitta- Pantazi, G. N. Philippou (Eds.), Proceedings of the fifth congress of the European Society for Research in Mathematics Education (pp. 1339-1348). Larnaka: Department of Education, University of Cyprus.

Ben-El-Mechaiekh, H., Buteau, C., \& Ralph, W. (2007). MICA: a novel direction in undergraduate mathematics teaching. Canadian Mathematics Society Notes, 39(6), 9-11.

Buteau, C., \& Muller, E. (2014). Teaching roles in a technology intensive core undergraduate mathematics course. In A. Clark-Wilson, O. Robutti, \& N. Sinclair (Eds.), The mathematics teacher in the digital era (pp. 163-185). Netherlands: Springer.

Buteau, C., Marshall, N., \& Muller, E. (2014). Learning university mathematics by creating and using fourteen 'microworlds'. In G. Futschek, C. Kynigos (Eds.), Proceedings of the 3rd International Constructionism Conference 2014 (pp. 401-406). Vienna: Österreichische Computer Gesellschaft (OCG).

Buteau, C., Muller, E., \& Marshall, N. (2015). When a university mathematics department adopted core mathematics courses of an unintentionally constructionist nature: really? Digital Experiences in Mathematics Education, 1(2-3), 133-155.

Cook, L. S., Smagorinsky, P., Fry, P. G., Konopak, B., \& Moore, C. (2002). Problems in developing a constructivist approach to teaching: one teacher's transition from teacher preparation to teaching. The Elementary School Journal, 102(5), 389-413.

Constructionism and Creativity 2014 Conference (n.d.). History of Constructionism. http:// constructionism2014.ifs.tuwien.ac.at/history.html.

Ernest, P. (2002). Empowerment in mathematics education. Philosophy of Mathematics Education Journal, $15,1-16$.

European Mathematical Society (2011). Position paper of the european mathematical society on the european commission's contributions to European research [online]. http://ec.europa.eu/research/csfri/pdf/ contributions/post/european_organisations/european_mathematical_society.pdf. Accessed 20 Jul 2015.

Goos, M., \& Soury-Lavergne, S. (2010). Teachers and teaching: Theoretical perspectives and classroom implementation. In C. Hoyles \& J.-B. Lagrange (Eds.), ICMI Study 17, technology revisited, ICMI study series (pp. 311-328). New York: Springer.

Gueudet, G., Buteau, C., Mesa, V., \& Misfeld, M. (2014). Instrumental and documentational approaches: from technology use to documentation systems in university mathematics education. Research of Mathematics Education, 16(2), 139-155.

Guin, D., \& Trouche, L. (1999). The complex process of converting tools into mathematical instruments. The case of calculators. International Journal of Computers for Mathematical Learning, 3(3), 195-227. 
Healy, L., \& Kynigos, C. (2010). Charting the microworld territory over time: design and construction in mathematics education. ZDM, 42(1), 63-76.

Hoyles, C. (1993). Microworlds/Schoolworlds: The transformation of an innovation. In C. Keitel \& K. Ruthven (Eds.), Learning from computers: mathematics education and technology NATO ASI, series F: computer and systems sciences (Vol. 121, pp. 1-17). Heidelburg: Springer.

Hoyles, C., \& Noss, R. (1992a). A pedagogy for mathematical microworlds. Educational Studies in Mathematics, 23(1), 31-57.

Hoyles, C., \& Noss, R. (Eds.). (1992b). Learning mathematics and logo. Cambridge: MIT Press.

Hoyles, C., \& Noss, R. (2008). Next steps in implementing Kaput's research programme. Educational Studies in Mathematics, 68(2), 85-97.

Hoyles, C., \& Noss, R. (2014). Why should we teach children to program, really? Invited keynote presentation at the Third International Constructionism Conference [video file]. Vienna: Österreichische Computer Gesellschaft. Retrieved from: https://www.youtube.com/watch?v=AVwtcI4bBCU\&list=UUldlJVVdukFpWdImz3NDCA.

Kafai, Y. B., \& Resnick, M. (1996). Constructionism in practice: designing, thinking, and learning in a digital world. Mahwah, NJ: Erlbaum, Routledge.

Kynigos, C. (2012). Constructionism: theory of learning or theory of design? In Proceedings of the 12th International Congress on Mathematical Education, Seoul.

Marshall, N., \& Buteau, C. (2014). Learning by designing and experimenting with interactive, dynamic mathematics exploratory objects. International Journal for Technology in Mathematics Education, 21(2), 49-64.

Mavrikis, M., Geraniou, E., Noss, R., \& Hoyles, C. (2008). Revisiting pedagogic strategies for supporting students' learning in mathematical microworlds. In Proceedings of the International Workshop on Intelligent Support for Exploratory Environments at EC-TEL (Vol. 8, 41-50).

McEvoy, M. (2013). Experimental mathematics, computers and the a priori. Synthese, 190(3), 397-412.

MICA URL (n.d.). Exploratory and learning objects created by Brock students in mathematics courses [Online]. Available: www.brocku.ca/mathematics/studentprojects.

Misfeldt, M., \& Ejsing-Duun, S. (2015). Learning mathematics through programming: an instrumental approach to potentials and pittfalls. In Proceedings of the 9th Congress of European Research on Mathematics Education. Prague.

Muller, E., Buteau, C., Ralph, W., \& Mgombelo, J. (2009). Learning mathematics through the design and implementation of exploratory and learning objects. International Journal for Technology in Mathematics Education, 16(2), 63-74.

Noss, R., \& Hoyles, C. (1996). Windows on mathematical meanings: learning cultures and computers (Vol. 17). Dordrecht: Kluwer.

Numerical Weather Prediction (n.d.). In Wikipedia. Retrieved 17 February, 2016, from https://en.wikipedia. org/wiki/Numerical_weather_prediction.

Papert, S. (1980a). Mindstorms: children, computers, and powerful ideas. New York: Basic Books.

Papert, S. (1980b). Computer-based microworlds as incubators for powerful ideas. In R. Taylor (Ed.), The computer in the school: tutor, tool, tutee (pp. 203-210). New York: Teacher's College Press.

Papert, S. (1990). A critique of technocentrism in thinking about the school of the future. Epistemology and Learning Group Memo No. 2 (September 1990), MIT Media Laboratory. Retrieved from http://www. papert.org/articles/ACritiqueofTechnocentrism.html.

Papert, S. (1991). Situating constructionism. In I. Harel \& S. Papert (Eds.), Constructionism (pp. 1-11). Norwood: Ablex Publishing Corporation.

Papert, S. (1996). An exploration in the space of mathematics educations. International Journal of Computers for Mathematical Learning, 1(1), 95-123.

Rabardel, P. (1995/2002). Les hommes et les technologies, une approche cognitives des instruments contemporains. Paris: Armand Colin.

Ralph, W. (2001). Mathematics takes an exciting new direction with MICA program. Brock Teaching, 1(1), 1.

S\& P 500 (n.d.). In Wikipedia. Retrieved 17 February, 2016, from https://en.wikipedia.org/wiki/S\%26P_500_ Index. Reference [S\&\#x0026, P 500 (n.d.). In Wikipedia. Retrieved 17 February 2016] was provided in the reference list; however, this was not mentioned or cited in the manuscript. As a rule, all the references given in the list of references should be cited in the body of a text. Please provide the location of where to insert the reference citation in the main body text.See comment inserted in Endnote $\# 4$ - related to Section 3 -EO 6

Springer Series in Computational Mathematics (n.d.). http://www.springer.com/series/797. 
Trouche, L. (2004). Managing complexity of human/machine interactions in computerized learning environments: guiding students' command process through instrumental orchestrations. International Journal of Computers for Mathematical Learning, 9, 281-307.

Trouche, L., \& Drijvers, P. (2010). Handheld technology for mathematics education: flashback into the future. ZDM: The International Journal on Mathematics Education, 42, 667-681.

US President's Information TEchnology Advisory Committee (2005). Computational science: Ensuring America's competitiveness. Retrieved from: https://www.nitrd.gov/pitac/reports/20050609 computational/computational.pdf.

Wilensky, U. (1995). Paradox, programming and learning probability. Journal of Mathematical Behavior, 14(2), 231-280.

Yin, R. (2003). Case study research: design and methods (4th ed.). Thousand Oaks: Sage Publications, Inc. 